http://jmscr.igmpublication.org/home/

ISSN (e)-2347-176x ISSN (p) 2455-0450

crossref DOI: https://dx.doi.org/10.18535/jmscr/v8i6.123

Journal Of Medical Science And Clinical Research

IGM Publication

An Official Publication of IGM Publication

\title{
Knowledge, attitude and practice of medical and dental undergraduate students regarding COVID 19
}

\author{
Authors

\section{Dr Ankita Singh ${ }^{1}$, Dr Anuradha $\mathbf{P}^{2}$, Dr Arpit Singh ${ }^{3 *}$, Dr Sahana $S^{4}$,} \\ Dr Sugandha Agarwal ${ }^{5}$, Dr Shweta Singh ${ }^{6}$
}

${ }^{1}$ PG Student, Department of Public Health Dentistry, Babu Banarasi Das College of Dental Sciences, Lucknow, Uttar Pradesh, India

${ }^{2}$ HOD \& Professor, Department of Public Health Dentistry, Babu Banarasi Das College of Dental Sciences,

Lucknow, Uttar Pradesh, India

${ }^{3}$ Assistant Professor, Department of Orthopedic Surgey, King George's Medical University Lucknow, Uttar Pradesh, India

${ }^{4}$ Reader, Department of Public Health Dentistry, Babu Banarasi Das College of Dental Sciences, Lucknow, Uttar Pradesh, India

${ }^{5,6}$ Senior Lecturer, Department of Public Health Dentistry, Babu Banarasi Das College of Dental Sciences, Lucknow, Uttar Pradesh, India

*Corresponding Author

\section{Dr Arpit Singh}

Assistant Professor, Department of Orthopedic Surgey, King George's Medical University Lucknow, Uttar Pradesh, India

\section{Abstract}

Introduction: COVID-19 disease is caused by SARS-CoV-2, it is a highly contagious disease. The World Health Organization has declared the ongoing outbreak to be a global Public Health Emergency. This study was conducted to assess the Knowledge, Attitude, and Practice (KAP) of medical and dental undergraduate $(U G)$ students at the time of COVID-19 pandemic.

Materials and Methods: An online questionnaire was distributed among medical and dental undergraduate students using a combination of convenience and snowball sampling. The questionnaire had 4 sections; the 1st section includes demographic details, whereas the $2 n d$, 3rd and 4 th sections had questions related to knowledge (6 questions), attitudes (5 questions) and practices (6 questions). The analysis was done using IBM SPSS for Windows, v. 20.0. Chi square test was applied and statistical significance level was set at $p<0.05$.

Results: The total number of the responses received was 1128 among that 414 were Medical undergraduate students and 714 were Dental undergraduate students. The overall achieved knowledge score indicate that $94.2 \%$ medical and $85.4 \%$ dental UG had good knowledge regarding COVID-19. All medical and $89.08 \%$ dental UG had a good attitude however, when it comes to practice only $72.4 \%$ medical and $70.3 \%$ dental UG scored in good category.

Conclusion: The knowledge and attitude of the UG students towards COVID-19 at the time of its outbreak is satisfactory, but the deficiencies in the practice need to be improved further. Emphasis on undergraduate training is necessary so as to minimize the risk of transmission of disease among students, also they are the future health care workers and also act as role model for the community.

Keywords: Knowledge, Attitude, Practice, COVID-19, medical undergraduate, dental undergraduate. 


\section{Introduction}

Coronavirus Disease 2019 (COVID-19) is a rapidly expanding pandemic caused by a novel coronavirus (SARS-COV-2) previously known as 2019-nCov. ${ }^{1,2}$ COVID-19 was first reported in December 2019 among patients with viral pneumonia symptoms in Wuhan, a city in China. ${ }^{3,4}$ As of 21st May 2020, over 50,90,118 cases and 3,29,735 deaths have been reported globally (Fig 1). ${ }^{5}$ United States of America has the highest number of cases globally $(15,93,039)$ and the highest number of deaths $(94,941) .{ }^{6}$ India is under lockdown since 22 march 2020, India has so far 1,12,442 cases and 3,438 death of COVID-19 till 21st May 2020.

This virus is transmitted from person-to-person through inhalation of aerosols from an infected individual. ${ }^{3}$ Old age and patients with comorbidity like hypertension, cardiac disease, lung disease, cancer, or diabetes are more prone to developed the disease. ${ }^{7},{ }^{8}$ Till now, there is no antiviral curative treatment or vaccine had been developed. ${ }^{9}$ Primary preventive measures include regular hand washing, social distancing, and respiratory hygiene involving covering of mouth and nose while coughing or sneezing. ${ }^{10,11}$

Healthcare workers (doctors and paramedical staff) are at the frontline of COVID-19 pandemic response and are exposed to dangers like pathogen exposure, long working hours, psychological distress, fatigue, physical violence and occupational burnout. ${ }^{12}$ At the time of writing the literature, medical and dental college for UG are closed in India but once it opens all students will have to take precautions and they must have adequate knowledge about COVID-19. A poor understanding of the disease among UG can result in delayed identification of patient and treatment leading to rapid spread of infections. Over 100 health workers have lost their lives to COVID-19, a tragedy to the world and a barrier to the fight against the disease. ${ }^{13}$ So this study was conducted to assess the knowledge, attitude and practice (KAP) of medical and dental UG students at the time of pandemic.

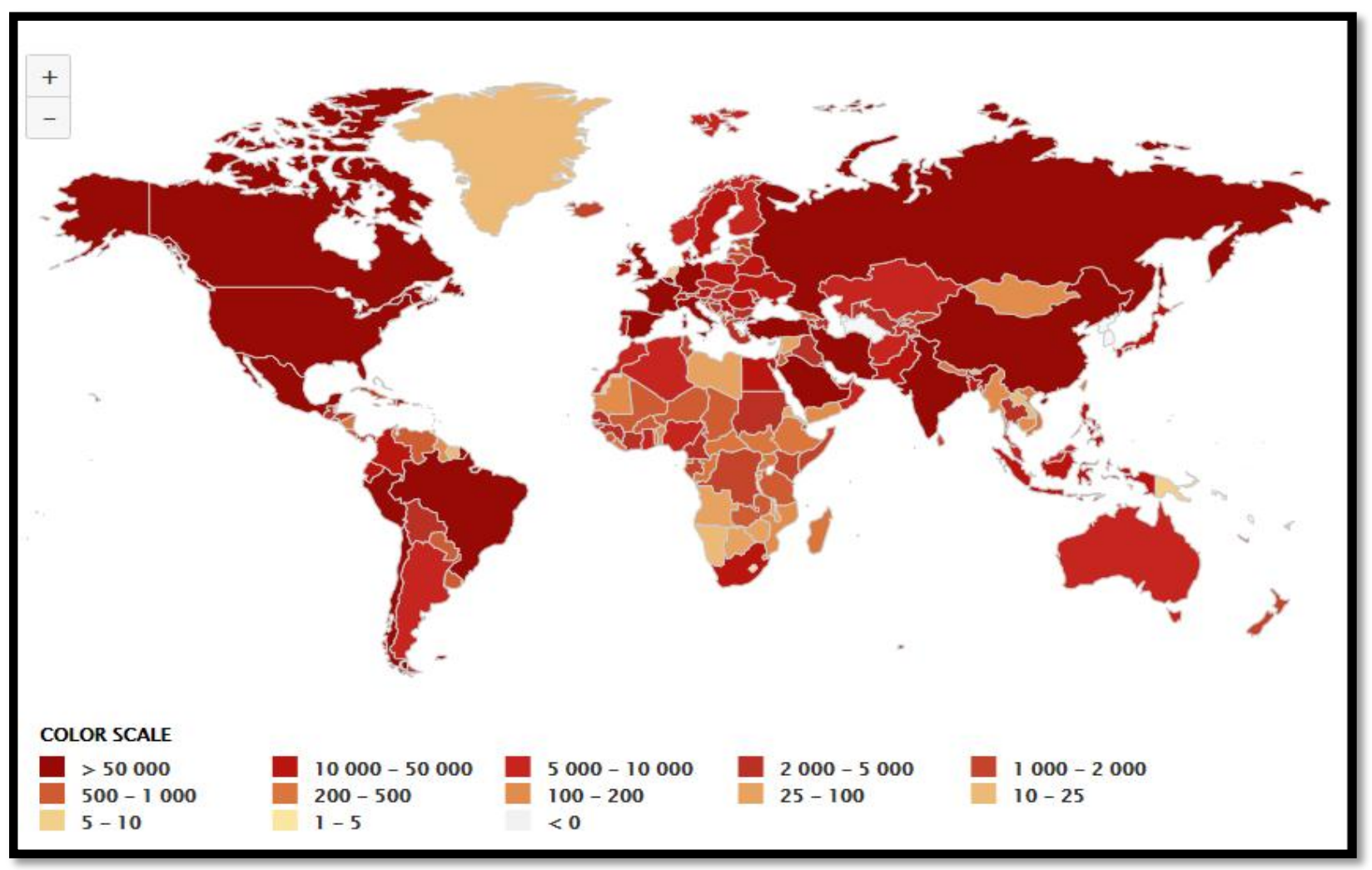

Fig 1: COVID-19 cases worldwide (till 21/05/2020) 


\section{Materials and Method}

This study was designed as a cross-sectional webbased survey. Prior to the start of the study, the questionnaire was designed, validated and pilot study was conducted.

The data was collected through an online questionnaire using Google forms. On clicking the link, the participants could view the survey questions. The questionnaire was created in form of a quiz. It was designed in English language. The questions were either in the form of a multiple choice answer or in the form of true, false, or no opinion. A total of 63 marks can be obtained and upon submitting the response the respondent could see his/her score.

The medical and dental UG respondent's consent to participate in the study (inclusion criteria) was included and they had complete freedom either to decline or accept this survey. All the data was accessed only by the principal investigator and to fill this survey no personal details like e-mail address, phone number, name, etc. were asked.

This study was conducted from 1 May 2020 to 15 May 2020. The questionnaire was distributed personally via a link and quick response (QR) code as well as posted on various social media platforms like Facebook, WhatsApp and telegram. In this survey convenience sampling i.e the researchers themselves contacted the UG students to participate in the study by sending them a link and snowball sampling i.e. the participating UG students were asked to forward the questionnaire to their batch mates/juniors/seniors so that maximal participation could occur.

The Google form included a short introduction regarding the objectives, procedures, the voluntary nature of participation, declarations of maintaining the confidentiality and anonymity.

The questionnaire was divided into 4 sections and had a total of 20 questions. The 1 st section contained demographic details like age, gender and educational qualification (medical UG /dental UG). This section did not have any marks. The 2nd, 3rd and 4th sections assessed the knowledge (6 questions), attitudes (5 questions) and practices
(6 questions) of the medical and dental UG students regarding COVID-19. A pilot study was done on $30 \mathrm{UG}$ students to validate the questionnaire and the Cronbach's alpha $(\alpha)$ was found to be 0.78 . The pilot study responses were excluded from the study.

\section{Scoring}

Scoring for knowledge, each correct answer was given a score of 4 while each wrong answer was given a score of 0 . In total there were 6 questions and each question in the knowledge section had only one correct answer and three wrong answers. This way, a respondent could score a maximum of 24 and a minimum of 0 in this section. For attitude, a score of 3 was given for right response and a score of 0 was given for wrong response. This way, a respondent could score a maximum of 15 and a minimum of 0 in the attitude section. For practice, each right response received a score of 4 while wrong response will received a score of 0 . Therefore, a respondent could score a maximum of 24 and a minimum of 0 in the practice section. The scores were also classified as poor, average, and good.

Data Analysis: The total KAP scores were calculated and coded data was sent to the statistician so that the confidentiality of the data could be maintained. The analysis was done using IBM SPSS for Windows, v. 20.0 (IBM Corp., Armonk, USA). Chi square test was applied and statistical significance level was set at $\mathrm{p}<0.05$.

\section{Results}

In our study, 1128 responses were received from the participants. The mean age of participants was 21.28 years. A total of 414 medical and 714 dental UG students participated in the study of which, $69.2 \%$ were females and $30.8 \%$ were males. Only $11.5 \%$ medical and $7.5 \%$ dental UG students responded with correct answers in all the three sections and obtained a score of 63 .

\section{Knowledge}

In the knowledge section, overall $91.79 \%$ medical and $88.98 \%$ dental UG students responded correctly, classification of the dental respondents 
on the basis of poor (0-8), average (9-16), and good (17-24) knowledge scores indicated 4, 100, and 610 students in respective categories in contrast to 24 and 390 medical respondents in average and good categories only. Statistically significant difference was noted in the medical and the dental UG students $(\mathrm{P}=0.003)$ [Graph 1].

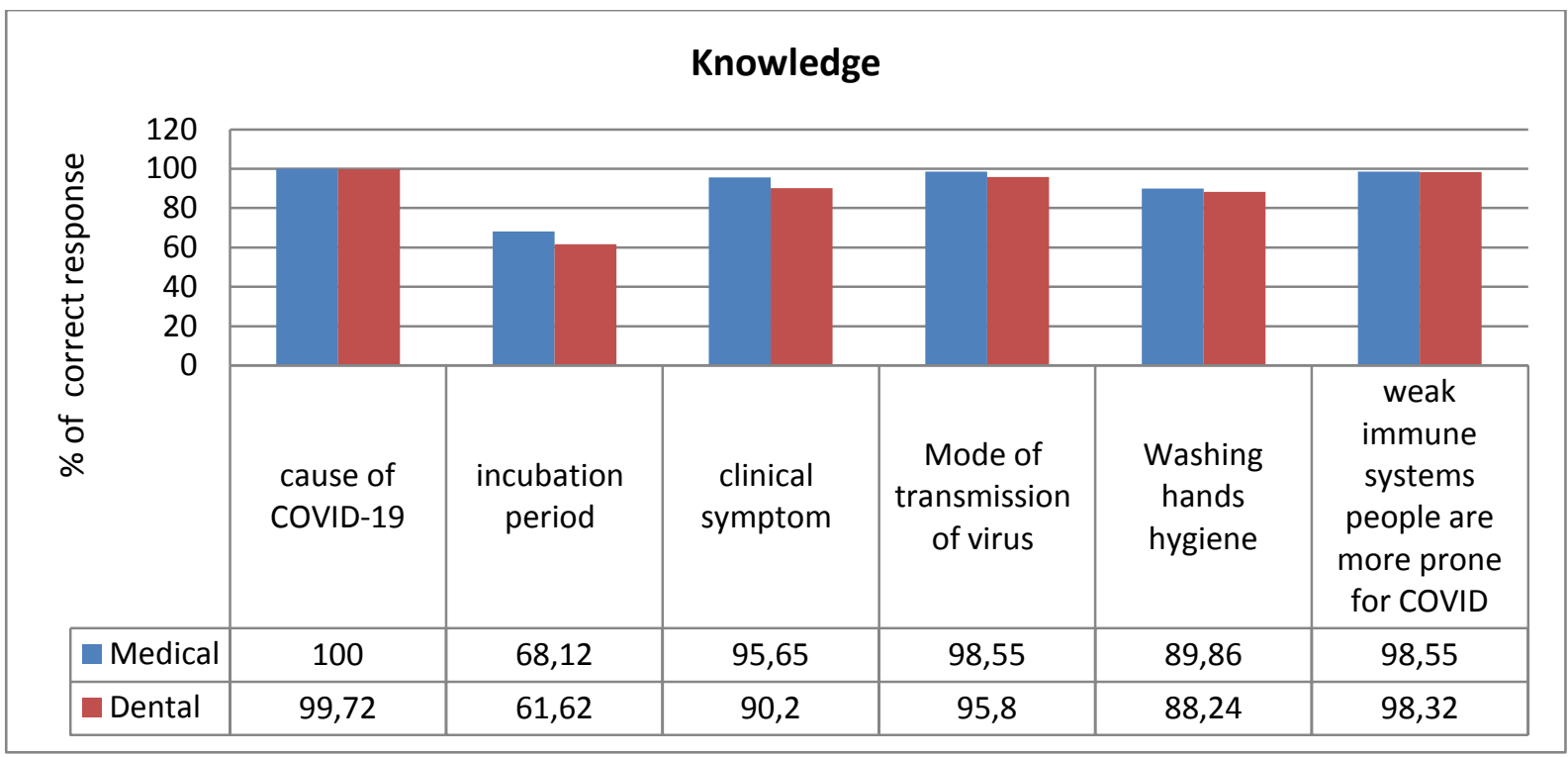

Graph 1: Knowledge of UG students (correct responses in \%)

\section{Attitude}

To evaluate the attitude of UG towards the disease, 5 questions were asked. Classification of the dental respondents on the basis of poor (0-5), average (6-10), and good (11-15) attitude scores indicated 2, 76, and 636 students in respective categories in contrast to all the medical respondents (414) in good categories. [Graph 2]. In this section, overall $89.47 \%$ medical and $86.83 \%$ dental UG responded correctly. Statistically significant differences were noted in the attitude of the medical and the dental students $(\mathrm{P}=0.001)$.

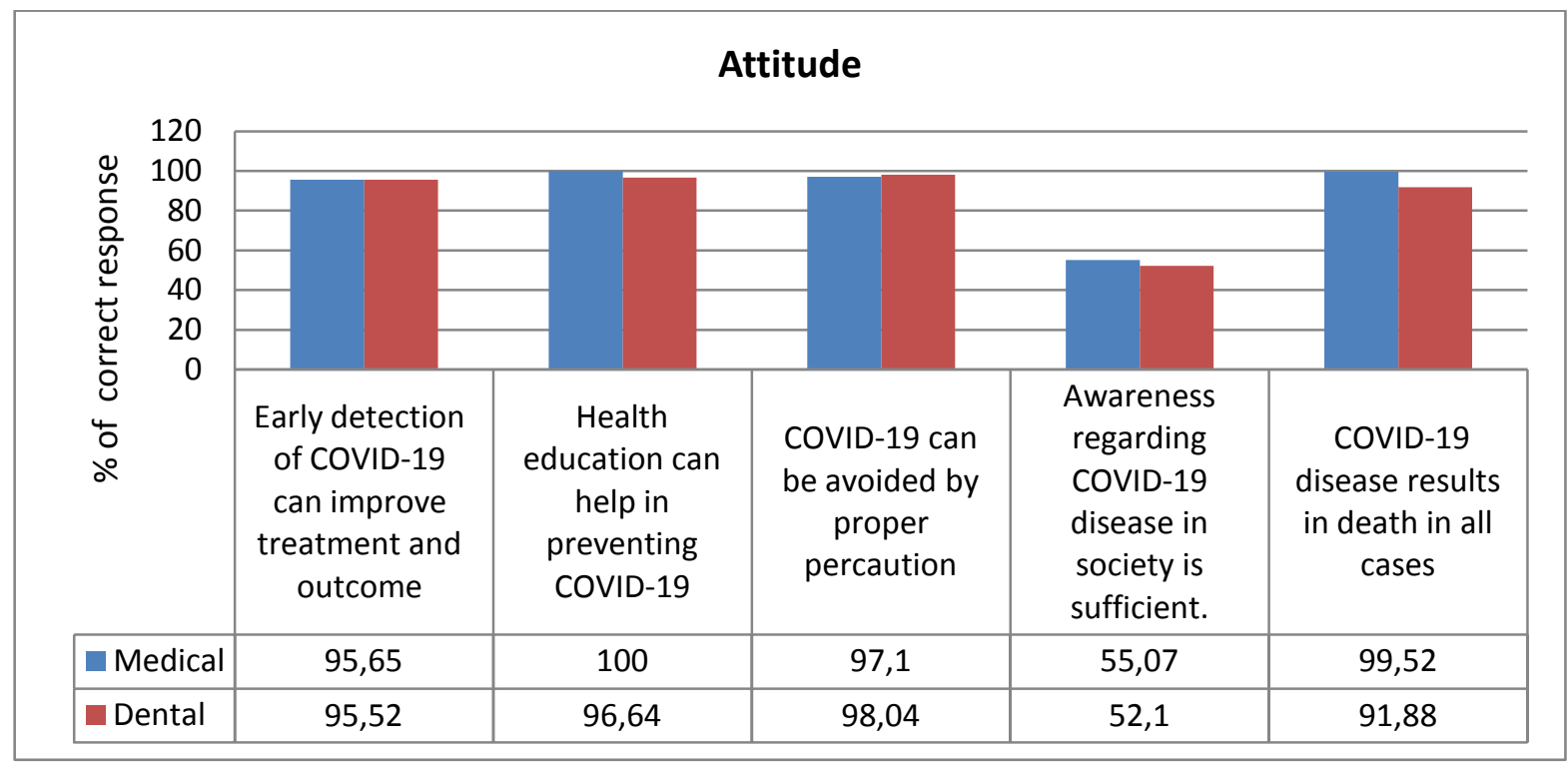

Graph 2: Attitude of UG students (correct responses in \%) 


\section{Practice}

Graph 3 shows statistically significant differences in the practice of both the medical and dental UG students $(\mathrm{P}=0.02)$. Classification of the dental UG on the basis of poor ( $0-4)$, average (5-8), and good (9-12) perception scores indicated 8, 204 and 502 respondent in respective categories in contrast to 12, 102 and 300 medical respondents in poor, average and good categories. However when it comes to practice, only $81.88 \%$ medical and $81.37 \%$ dental UG students responded correctly.

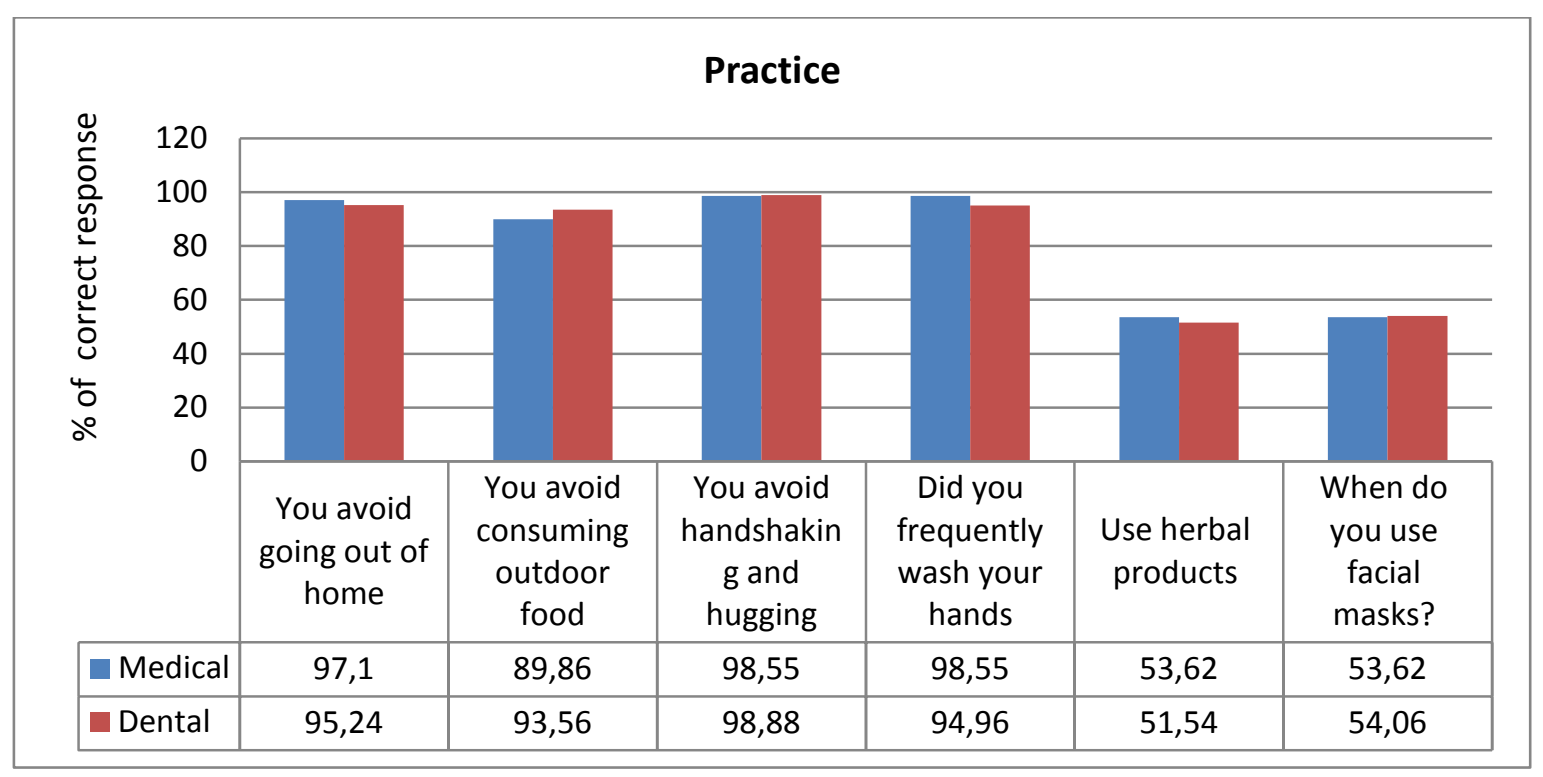

Graph 3: Practice of UG students (correct responses in \%)

Table 1: percentage of UG students in good, average and poor category

\begin{tabular}{|lccc}
\hline Knowledge & Good $(17-24)$ & Average $(9-16)$ & Poor $(0-8)$ \\
Medical UG & $94.20 \%$ & $5.80 \%$ & $0.00 \%$ \\
Dental UG & $85.43 \%$ & $14.01 \%$ & $0.56 \%$ \\
\hline Attitude & Good (11-15) & Average $(6-10)$ & Poor $(0-5)$ \\
Medical UG & $100.00 \%$ & $0.00 \%$ & $0.00 \%$ \\
Dental UG & $89.08 \%$ & $10.64 \%$ & $0.28 \%$ \\
& & & \\
\hline Practice & Good $(17-24)$ & Average $(9-16)$ & Poor $(0-8)$ \\
Medical UG & $72.46 \%$ & $24.64 \%$ & $2.90 \%$ \\
Dental UG & $70.31 \%$ & $28.57 \%$ & $1.12 \%$
\end{tabular}

\section{Discussion}

To the best of our knowledge, this is the first study to investigate the KAP towards COVID 19 among both medical and dental UG students in India. The recent spread of COIVD-19 disease and its consequences have gripped the entire community and has caused wide spread public health concerns. Based on our findings, the KAP towards COVID-19 score was significantly higher among medical UG as compared to dental UG.
Based on the knowledge scores of the participants, an overall correct rate among medical and dental UG was $94.2 \%$ and $85.43 \%$, demonstrated that the majority of participants had knowledge about COVID-19.

Inspite of all the efforts taken by the Health Organizations and Government, the number of cases are rising every day, because the nature of the spread of the infection and the difficulty in its containment. ${ }^{14}$ This is a zoonotic infection 
similar to other corona virus infections and is originated from bats and later transmitted to humans. ${ }^{15}$ Once the person acquires the disease, the virus will multiply rapidly in the nasopharyngeal and salivary secretions. Virus spread is predominantly through respiratory droplets or through contact with contaminated surfaces.

Knowledge regarding viral transmission in our study was $100 \%$ among medical UG and $99.7 \%$ dental UG which was similar to study conducted by Vishwesh Agarwal et al ${ }^{16}$ where $97.7 \%$ medical UG said the same. However, the result of incubation period was in contrast to our study.

India is under lockdown and all medical and dental colleges are closed for UG, however once it open these UG will encounter such patients during their clinical posting and will have to act diligently not only to provide medical and dental care but at the same time prevent nosocomial spread of the infection. ${ }^{17,18}$ The closure of medical and dental colleges has led to innovative methods of delivering education, ensuring that students continue to receive teaching, albeit different methods. ${ }^{19}$ Lectures have rapidly been developed to be delivered online as webinars using various platforms such as Zoom, Webex meet, Google meet etc. These technologically enhanced approaches already being proven to have high levels of engagement with medical and dental students. ${ }^{20}$

It is important to remember that COVID-19 does not differentiate between borders, ethnicities, disability status, age or gender. ${ }^{21}$ The early death cases of COVID-19 outbreak occurred primarily in elderly people, possibly due to weak immune system $^{22,23}$; around $98 \%$ UG agrees with the same in our study.

A face mask may help reduce the spread of infection in the community by decreasing the excretion of respiratory droplets from infected individuals who may not even know they are infected and before they develop any symptoms. ${ }^{24}$ In our study only $53 \%$ of UG wear mask in public places. All the medical UG and $89.08 \%$ dental UG had a positive attitude towards COVID-19. However when it came to practice only $72.4 \%$ medical and $70.3 \%$ dental UG follow it (table 1).

Health care professionals are having higher chances of getting infected. So, it is essential that at the undergraduate students must be educated, empowered and provided appropriate and relevant knowledge regarding the disease. The infection control protocols, the personal protective equipment for safety and handling even asymptomatic patients is of utmost importance for these students. This will make them well prepared when the colleges will re-open and also protect them from getting infected.

This study has given an insight tounderstand the primary level of KAP among the undergraduate students regarding this disease. Our study has involved the undergraduate students from first year to interns of both medical and dental stream as this is a generalized epidemic related topic (COVID-19). Making the first and second year students aware of different aspects of the infection will enhance their practice of hygiene further. Furthermore, we thought that it is a best opportunity for UG students to get involved in a questionnaire study as they might get exposed towards different types of research studies and may develop interest in the same.

\section{Limitation and Recommendation}

The limitations of this study was, there is no comparative assessment between the different academic year students and also there is no control over the previous knowledge gained by the students through authenticated training courses on the disease which may act as a confounding factor. Further research studies can be conducted on the comparative assessment of the KAP amongst the different academic year students.

\section{Conclusions}

The knowledge and attitude of the UG students towards COVID-19 at the time of its outbreak is satisfactory, but the deficiencies in the practice need to be improved further. Emphasis on 
undergraduate training is necessary so as to minimize the risk of transmission of disease in students, also they are the future doctors and also act as role model for the community. Conducting periodic webinars for educational intervention for all UG students could be a useful and a safe tool to prepare them for this pandemic.

\section{Acknowledgments}

We thank all the study participants for their voluntary participation and for providing essential information.

\section{Funding: None}

\section{Conflict of interest: None}

\section{References}

1. World Health Organization. Coronavirus disease 2019 (COVID-19) Situation Report - 51. Geneva: WHO. (2020). Available online at: www.who.int/ emergencies/diseases/novel-coronavirus-

2019/situation-reports (accessed March 18, 2020).

2. Zhu N, Zhang D, Wang W, Li X, Yang B, Song $\mathrm{J}$, et al. A novel coronavirus from patients with pneumonia in China, 2019. N Engl J Med. (2020) 382:727- 33. doi: 10.1056/NEJMoa2001017

3. Li Q, Guan X, Wu P, Wang X, Zhou L, Tong $\mathrm{Y}$, et al. Early transmission dynamics in Wuhan, China, of novel coronavirus-infected pneumonia. N Engl J Med. (2020) 382:1199-207. doi: 10.1056/NEJMoa2001316

4. Lu H, Stratton CW, Tang YW. Outbreak of pneumonia of unknown etiology in Wuhan, China: the mystery and the miracle. J Med Virol. (2020) 92:401-2. doi: 10.1002/jmv.25678

5. Coronavirus Outbreak. Available at: https://www.worldometers.

info/coronavirus/. Accessed 21 may 2020.

6. World Health Organisation. Coronavirus disease 2019 (COVID-19) Situation Report - 90. Geneva: WHO. (2020).
Available online at: www.who.int/ emergencies/diseases/novel-coronavirus2019/situation-reports (accessed may 21, 2020).

7. Tao N. An analysis on reasons of SARSinduced psychological panic among students. Journal of Anhui Institute of Education. 2003; 21: 78-9.

8. General Office of the National Health Commission of the People's Republic of China. Guideline for the diagnosis and treatment of 2019 novel coronavirus (2019-nCoV) infected pneumonia (The Third Trial Version). 2020. http://www.nhc.gov.cn/yzygj/s7653p/2020 01/f492c9153ea9437bb587ce2ffc bee1fa.shtml (access 16 may, 2020).

9. Ankita Singh, Anuradha P, Sahana S, Sugandha Agarwal, Shweta Singh, "COVID-19 Pandemic: As we know it", IJDSIR- May - 2020, Vol. - 3, Issue -3, P. No. $322-332$.

10. Taber KS. The Use of Cronbach's Alpha When Developing and Reporting Research Instruments in Science Education. Research in Science Education. 2018; 48: 1273-96.

11. Zhou X, Xiu C, Chu Q. Prevention and treatment knowledge and attitudes towards SARS of urban residents in Qingdao. Prev Med Trib. 2004; 10: 407-8.

12. Liu Z, Gao H, Zhang S. Prevention and treatment knowledge towards SARS of urban population in Jinan. Prev Med Trib. 2004; 10: 659-60.

13. Chen S, Qiu Z, Xu L, Chen J, Lin Y, Yang $\mathrm{Y}$, et al. People groups' responses to SARS in the community. Chinese Rural Health Service Administration. 2003; 23: 15-8.

14. Du Toit A. Outbreak of a novel coronavirus, Nat Rev Microbiol 18 (123) (2020), https://doi.org/10.1038/s41579-020-03320 . 
15. Perlman S. Another decade, another coronavirus. N Engl J Med 2020. DOI: 10.1056/NEJMe2001126.

16. https://www.medrxiv.org/content/10.1101/ 2020.04.11.20061333v2

17. Huang C, Wang Y, LiX, Ren L, Zhao J, $\mathrm{Hu} \mathrm{Y}$, et al. Clinical features of patients infected with 2019 novel coronavirus in Wuhan, China. Lancet. 2020; 395 (10223):497-506 https://doi.org/10.1016/S01406736(20)301 83-5.

18. Lu H, Drug treatment options for the 2019-new coronavirus(2019-nCoV),

Biosci. Trends (2020), https://doi.org/10.5582/bst.2020.01020.

19. Preeti Sandhu \& Maisie de Wolf (2020) The impact of COVID-19 on the undergraduate medical curriculum, Medical Education Online, 25:1, 1764740, DOI: $10.1080 / 10872981.2020 .1764740$

20. Kay D, Pasarica M. Using technology to increase student (and faculty satisfaction with0 engagement in medical education. Adv Physiol Educ. 2019;43 (3):408-413.

21. https://www.who.int/docs/defaultsource/coronaviruse/key-messages-andactions-for-covid-19-prevention-andcontrol-in-schools-march2020.pdf?sfvrsn=baf81d52_4\&gclid=EAIa IQobChMIsdfP997P6QIVFbaWCh060Qs2 EAAYASAAEgLeDPD_BwE

22. Wang W, Tang J, Wei F. Updated understanding of the outbreak of 2019 novel coronavirus (2019-nCoV) in Wuhan, China. J Med Virol. 2020;92 (4): 441-7.

23. The Novel Chinese Coronavirus 10.1111/eci.13209 Bassetti M, Vena A, Giacobbe DR. The Novel Chinese Coronavirus (2019nCoV) Infections: challenges for fighting the storm, Eur. J.Clin. Invest. (2020) e13209, https://doi.org/10.1111/eci.13209.
24. https://www.ecdc.europa.eu/sites/default/fi les/documents/COVID-19-use-face-maskscommunity.pdf 